\title{
Stable carbon isotope ratios of ethane over the North Pacific: Atmospheric measurements and global chemical transport modeling
}

\author{
Takuya Saito, ${ }^{1,2}$ Olaf Stein, ${ }^{3}$ Urumu Tsunogai, ${ }^{4}$ Kimitaka Kawamura, ${ }^{1}$ \\ Takeshi Nakatsuka, ${ }^{1,5}$ Toshitaka Gamo, ${ }^{4,6}$ and Naohiro Yoshida ${ }^{7}$
}

Received 9 June 2010; revised 8 November 2010; accepted 22 November 2010; published 27 January 2011.

[1] The atmospheric mixing ratios of ethane and its stable carbon isotope ratios $\left(\delta^{13} \mathrm{C}\right)$ were measured over the North Pacific $\left(2^{\circ} \mathrm{N}\right.$ to $38^{\circ} \mathrm{N}, 140^{\circ} \mathrm{E}$ to $\left.90^{\circ} \mathrm{W}\right)$ during oceanographic cruises in summer and autumn. The measured mixing ratios were relatively low (mostly $<1 \mathrm{ppbv}$ ) over the North Pacific, whereas elevated ethane levels ( $>1 \mathrm{ppbv})$ were observed over the western North Pacific near Japan, with lower $\delta^{13} \mathrm{C}$ values (approximately $-25 \%$ ), suggesting recent emissions from neighboring source regions. The most ${ }^{13} \mathrm{C}$-enriched values of ethane (approximately $-16 \%$ ) were observed over the western equatorial Pacific rather than the central and eastern equatorial Pacific. This is likely caused by the kinetic isotope effect (KIE) for the removal of ethane during the atmospheric transport from potential upwind source regions to the most remote region under the prevailing trade easterly winds. The measurements were compared with the results of a global chemical transport model including two ethane isotopologues $\left({ }^{12} \mathrm{C}_{2} \mathrm{H}_{6}\right.$ and $\left.{ }^{13} \mathrm{C}_{2} \mathrm{H}_{6}\right)$. The model-estimated $\delta^{13} \mathrm{C}$ values were too high compared with the observations. It is likely that this discrepancy is partly due to an approximately $40 \%$ overestimation of the reported KIE for the reaction between ethane and $\mathrm{OH}$ radicals.

Citation: Saito, T., O. Stein, U. Tsunogai, K. Kawamura, T. Nakatsuka, T. Gamo, and N. Yoshida (2011), Stable carbon isotope ratios of ethane over the North Pacific: Atmospheric measurements and global chemical transport modeling, J. Geophys. Res., 116, D02308, doi:10.1029/2010JD014602.

\section{Introduction}

[2] Ethane, the second most abundant hydrocarbon in the remote atmosphere after methane, acts as a precursor of ozone and other photochemical oxidants (e.g., acetaldehyde and peroxyacetyl nitrate) through photochemical degradation, mainly by $\mathrm{OH}$ radicals. The atmospheric lifetime of ethane ( 2 months [Rudolph, 1995]) is long enough for it to undergo long-range transport from source regions to remote areas but short enough for ethane mixing ratios to vary substantially both spatially and temporally. The mixing ratios of ethane, in combination with those of other nonmethane

\footnotetext{
${ }^{1}$ Institute of Low Temperature Science, Hokkaido University, Sapporo, Japan.

${ }^{2}$ Now at Environmental Chemistry Division, National Institute for Environmental Studies, Ibaraki, Japan.

${ }^{3}$ Institut für Energie- und Klimaforschung - Troposphäre (IEK-8), Forschungszentrum Jülich, Jülich, Germany.

${ }^{4}$ Graduate School of Science, Hokkaido University, Sapporo, Japan.

${ }^{5}$ Now at Graduate School of Environmental Studies, Nagoya University, Nagoya, Japan.

${ }^{6}$ Now at Ocean Research Institute, University of Tokyo, Tokyo, Japan.

${ }^{7}$ Department of Environmental Science and Technology, Interdisciplinary Graduate School of Science and Engineering, Tokyo Institute of Technology, Yokohama, Japan.
}

Copyright 2011 by the American Geophysical Union. 0148-0227/11/2010JD014602 hydrocarbons, are therefore useful indicators of atmospheric oxidation and transport processes on regional, hemispheric, and global scales [Blake et al., 1996a; Goldstein et al., 1995; Helmig et al., 2008; Parrish et al., 1992]. Ethane can also be used as a unique tracer that provides constraints on the fossil fuel sources of methane [Xiao et al., 2008].

[3] Stable carbon isotope ratio $\left(\delta^{13} \mathrm{C}\right)$ measurements of ethane can provide additional insight into its sources, sinks, and distributions in the atmosphere. Although the number of such studies is still quite limited [e.g., Nara et al., 2007; Rudolph et al., 1997; Tsunogai et al., 1999], a few studies [Saito et al., 2002, 2009] have shown that atmospheric $\delta^{13} \mathrm{C}$ measurements of ethane can be used to estimate the extent of photochemical aging within the theoretical framework of the "isotopic hydrocarbon clock" [Rudolph and Czuba, 2000]. Another approach to the interpretation of $\delta^{13} \mathrm{C}$ observations is to use a numerical model. Volatile organic compounds (VOCs), which have relatively long lifetimes (approximately $>1$ year) and are well mixed in the atmosphere, allow the use of a simple isotope mass balance model to constrain the atmospheric budget [Bill et al., 2004; Keppler et al., 2005; Saito and Yokouchi, 2008; Thompson et al., 2002]. In contrast, more reactive VOCs, such as ethane, require an isotopeinclusive global chemical transport model.

[4] Thompson et al. [2003] have developed such a global chemical transport model for ethane and benzene; their model 
treats the emissions and chemistry simply by using a uniform stable carbon isotope ratio for all sources and a prescribed $\mathrm{OH}$ radical concentration. A more comprehensive model with source-specific isotope ratios of ethane and detailed model chemistry has been presented by Stein and Rudolph [2007]. These studies have demonstrated that comparison of atmospheric $\delta^{13} \mathrm{C}$ measurements with estimates from a chemical transport model can provide a useful test of our understanding of the emissions, atmospheric transport processes, and chemical reactions of VOCs. However, to our knowledge, no study has directly compared the ambient $\delta^{13} \mathrm{C}$ measurements and model results corresponding to the temporal and spatial observations for specific years.

[5] Here, we present stable carbon isotope measurements of ethane in the marine atmosphere during two oceanographic cruises over the North Pacific. We compare these with the results from a three-dimensional chemical transport model, and we discuss the factors controlling the $\delta^{13} \mathrm{C}$ of ethane in the background marine atmosphere.

\section{Experimental Procedure}

[6] Eighty-eight air samples were collected over the North Pacific during two cruises: (1) the trans-Pacific cruise of R/V Shoyo-maru (Japan Fisheries Agency) between Japan and Mexico in September-October 1999 (40 samples, $2^{\circ} \mathrm{N}$ to $35^{\circ} \mathrm{N}, 145^{\circ} \mathrm{E}$ to $90^{\circ} \mathrm{W}$ ) and (2) the western North Pacific cruise of R/V Mirai (Japan Marine Science and Technology) in June-July $2000\left(48\right.$ samples, $7^{\circ} \mathrm{N}$ to $38^{\circ} \mathrm{N}, 140^{\circ} \mathrm{E}$ to $142^{\circ} \mathrm{E}$ ). Air samples were taken on the front of the upper deck using pre-evacuated $6 \mathrm{~L}$ fused-silica-lined stainless steel canisters (Silico-can, Restek Co., Ltd.), which were kept until the end of the cruises before being transported to the laboratory for the analysis.

[7] Stable carbon isotope ratios of ethane were measured with a cryogenic vacuum extraction line and by gas chromatography - combustion - isotope ratio mass spectrometry (GC-C-IRMS) in accordance with the method of Rudolph et al. [1997]. Details of the experimental setup have been documented by Tsunogai et al. [1999]. Briefly, each air sample (approximately $6 \mathrm{~L}$ ) was condensed in a three-stage preconcentration process in a bath of liquid $\mathrm{N}_{2}$. During the procedure, bulk air gases (mostly $\mathrm{N}_{2}$ and $\mathrm{O}_{2}$ ), water vapor, and $\mathrm{CO}_{2}$ were removed. The purified air sample including ethane was then introduced to the gas chromatograph equipped with a PoraPLOT-Q capillary column ( $25 \mathrm{~m}$ long $\times 0.32 \mathrm{~mm}$ internal diameter) after a cryofocusing of ethane and other hydrocarbons at liquid $\mathrm{N}_{2}$ temperature at the head of the capillary column. The stable carbon isotope ratios of the ethane were measured by IRMS (Finnigan MAT 252) in continuous flow mode, following combustion of the ethane to $\mathrm{CO}_{2}$.

[8] The accuracy of the isotopic measurements was estimated to be better than $0.3 \%$ versus Peedee belemnite (PDB) by the measurement of a U.S. National Institute of Standards and Technology RM 8560 (International Atomic Energy Agency (IAEA) NGS2) isotopic standard. The reproducibilities derived from repeated analyses of a working standard were less than $0.5 \%$ for $\mathrm{GC}$ injection of $>200 \mathrm{pmol} \mathrm{C},<1.5 \%$ for 80 to $200 \mathrm{pmol} \mathrm{C}$, and $<2 \%$ for 30 to $80 \mathrm{pmol} \mathrm{C}$. The working standard, containing 1-10 ppmv hydrocarbons, was made from the ambient air in our laboratory. Calibrations of the measurement system were also performed with diluted standard down to levels of $100 \mathrm{pptv}$, and the results were consistent with those obtained from the working standard gas. The mixing ratio of ethane was calculated by comparing the peak area of ${ }^{44} \mathrm{CO}_{2}(\mathrm{~m} / \mathrm{z} 44)$ with that of a calibrated amount of working standard gas mixture. The reproducibility of the concentration measurements was better than $10 \%$. We do not report on nonmethane hydrocarbons other than ethane, due to the large uncertainties $(> \pm 4 \%$ ) caused by low mixing ratios.

\section{Results and Discussion}

\subsection{Horizontal Variations in Ethane Mixing Ratios and $\delta^{13} \mathrm{C}$}

[9] Measurements of atmospheric ethane showed relatively low mixing ratios (mostly below 1 ppbv) over the North Pacific, whereas mixing ratios higher than 1 ppbv were observed over the western North Pacific near Japan (Figure 1). The elevated ethane levels were attributed to recent inputs of terrestrial ethane into the air masses, because back trajectories showed that the air masses in question had passed over Japan in the previous 5 days (Figure 2). The back trajectories also showed that the air samples with low ethane mixing ratios $(<1 \mathrm{ppbv})$ were part of pristine maritime air masses transported by trade winds: northeasterly to the north and southeasterly to the south of the Intertropical Convergence Zone (ITCZ), which locates at about $10^{\circ} \mathrm{N}$. The mean mixing ratios for both cruises $(0.45 \pm 0.23 \mathrm{ppbv})$ were comparable to those previously reported for the North Pacific in summer-autumn, namely $0.76 \pm 0.41$ pptv during the Pacific Exploratory Mission over the western Pacific (PEM-West A) ( $<2 \mathrm{~km}$ altitude) [Blake et al., 1996b], and 0.5 to $0.7 \mathrm{ppbv}$ at Hawaii and about 0.3 ppbv for the equatorial western Pacific [Blake, 2005]; the data for ethane mixing ratios have been compiled by Xiao et al. [2008].

[10] The stable carbon isotope ratios of ethane ranged from $-16.0 \%$ to $-25.4 \%$, with a mean of $-20.1 \%$ o $( \pm 2.3 \%$ ) over both cruises. The $\delta^{13} \mathrm{C}$ values during the western North Pacific cruise were generally higher than those during the trans-Pacific cruise in similar latitudes. Because the mean $\mathrm{OH}$ radical concentrations were likely to have been similar during the two cruises [Spivakovsky et al., 2000], the high ${ }^{13} \mathrm{C}$ enrichment of ethane over the low latitudinal western North Pacific $\left(7^{\circ} \mathrm{N}-35^{\circ} \mathrm{N}\right)$ suggests that the air masses over this region had been transported for a longer time than those over the central and the equatorial eastern Pacific. This is consistent with the fact that the low-latitudinal western North Pacific is far away from potential upwind source regions (e.g., North and South America) than the central and the equatorial eastern Pacific (see Figure 2).

[11] We compared our results during the western North Pacific cruise with those obtained in previous studies in similar regions. Our result for mixing ratio $(0.40 \pm 0.13 \mathrm{ppbv})$ was lower than those of the previous studies; $1.02 \pm 0.46 \mathrm{ppbv}$ $\left(6^{\circ} \mathrm{N}-35^{\circ} \mathrm{N}\right.$ [Tsunogai et al., 1999]) and $0.80 \pm 0.57 \mathrm{ppbv}$ $\left(2^{\circ} \mathrm{N}-31^{\circ} \mathrm{N}\right.$ [Nara et al., 2007]), while the $\delta^{13} \mathrm{C}$ value in this study $(-19.1 \% \circ \pm 2.3 \%$ ) was higher than the previous studies; $-24.4 \%$ o $\pm 2.0 \%$ [Tsunogai et al., 1999$]$ and $-23.7 \%$ o $\pm 2.4 \%$ [Nara et al., 2007]. In the remote areas, mixing ratios and $\delta^{13} \mathrm{C}$ of ethane are largely controlled by photochemical degradation of ethane mainly by $\mathrm{OH}$ radicals. Thus, these differences likely reflect seasonal variations in ethane, with 
a)

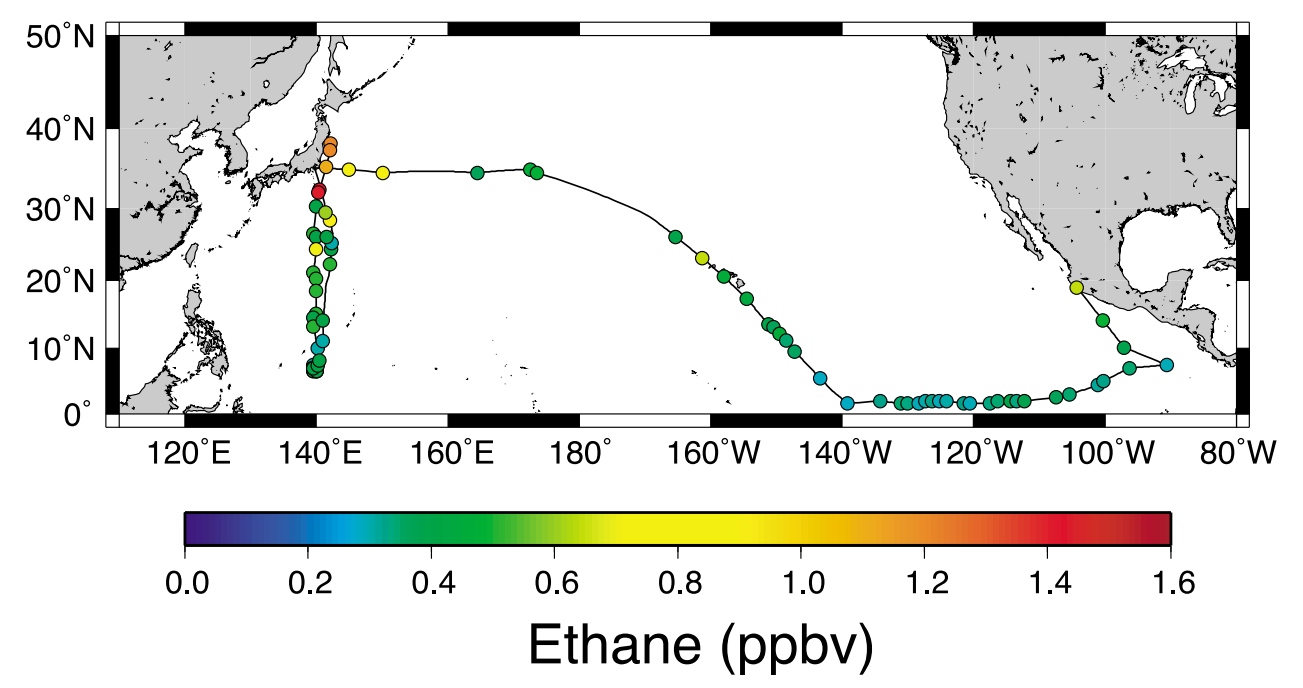

b)
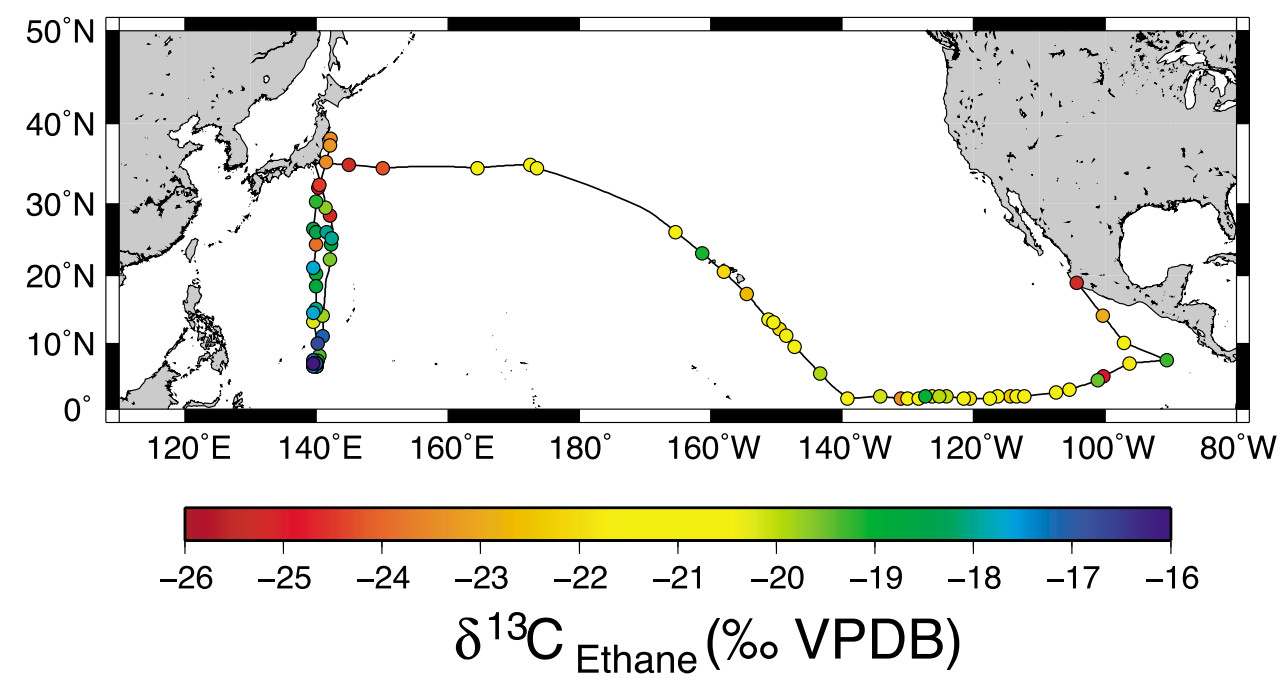

Figure 1. Observed (a) mixing ratios and (b) stable carbon isotope ratios of ethane from the trans-Pacific cruise between Japan and Mexico in September-October $1999\left(2^{\circ} \mathrm{N}-35^{\circ} \mathrm{N}, 145^{\circ} \mathrm{E}-90^{\circ} \mathrm{W}\right)$, and the western North Pacific cruise in June-July $2000\left(7^{\circ} \mathrm{N}-38^{\circ} \mathrm{N}, 140^{\circ} \mathrm{E}-142^{\circ} \mathrm{E}\right)$. Black lines show the cruise tracks.

lower mixing ratios and higher $\delta^{13} \mathrm{C}$ values in summerautumn (this study) than in winter (the previous studies), largely because of seasonal variation in $\mathrm{OH}$ radical concentrations (low in winter and high in summer) [Spivakovsky et al., 2000]. In addition, these differences are likely related to seasonal changes in the prevailing winds. Air masses transported by the northeasterly winds in summer-autumn travel over remote oceans and are not influenced by recent terrestrial emissions [e.g., Blake et al., 1996b; Saito et al., 2004], whereas westerly winds in winter-spring could transport pollution from East or Southeast Asia [e.g., Blake et al., 1997; Saito et al., 2000, 2009].

[12] We examined a relation between the mixing ratios of ethane and $\delta^{13} \mathrm{C}$ values for the two cruises (Figure 3). The increase in $\delta^{13} \mathrm{C}$ with decreasing mixing ratio is consistent with positive isotopic fractionation during the removal of ethane, mainly due to $\mathrm{OH}$ radicals, in the atmosphere (kinetic isotope effect; KIE). However, the slopes of least squares fit lines for the measurements (apparent KIE, $\varepsilon_{\text {app }}=5.4 \% \pm \pm$ $0.7 \%$ for the western North Pacific cruise and $\varepsilon_{\text {app }}=2.9 \%$ t $1.9 \%$ for the trans-Pacific cruise) were smaller than those obtained for the reaction with $\mathrm{OH}$ radicals in a laboratory $\left(\mathrm{KIE}_{\mathrm{OH}}, \varepsilon_{\mathrm{OH}}=8.57 \%\right.$ $\pm 1.95 \%$ [Anderson et al., 2004]). To our knowledge, all previous studies on ambient $\delta^{13} \mathrm{C}$ measurement of ethane have also reported lower apparent KIEs than the laboratory-determined $\mathrm{KIE}_{\mathrm{OH}} ; \varepsilon_{\mathrm{app}}=3 \% \pm 1 \%$ o [Tsunogai et al., 1999], $\varepsilon_{\mathrm{app}}=5.5 \% \mathrm{\%} \pm 1.3 \%$ [Saito et al. $2002], \varepsilon_{\text {app }}=3.3 \% \pm 1.7 \%$ [Nara et al., 2007], $\varepsilon_{\text {app }}=$ $2.8 \% \pm 0.6 \%$ [Saito et al., 2009]. Because atmospheric mixing or dilution causes a more pronounced change in the mixing ratio than in the $\delta^{13} \mathrm{C}$, the lower apparent KIEs might be due partly to mixing or dilution processes. In section 3.2, we discuss another possible implication of these lower apparent KIEs: overestimation of $\mathrm{KIE}_{\mathrm{OH}}$. 


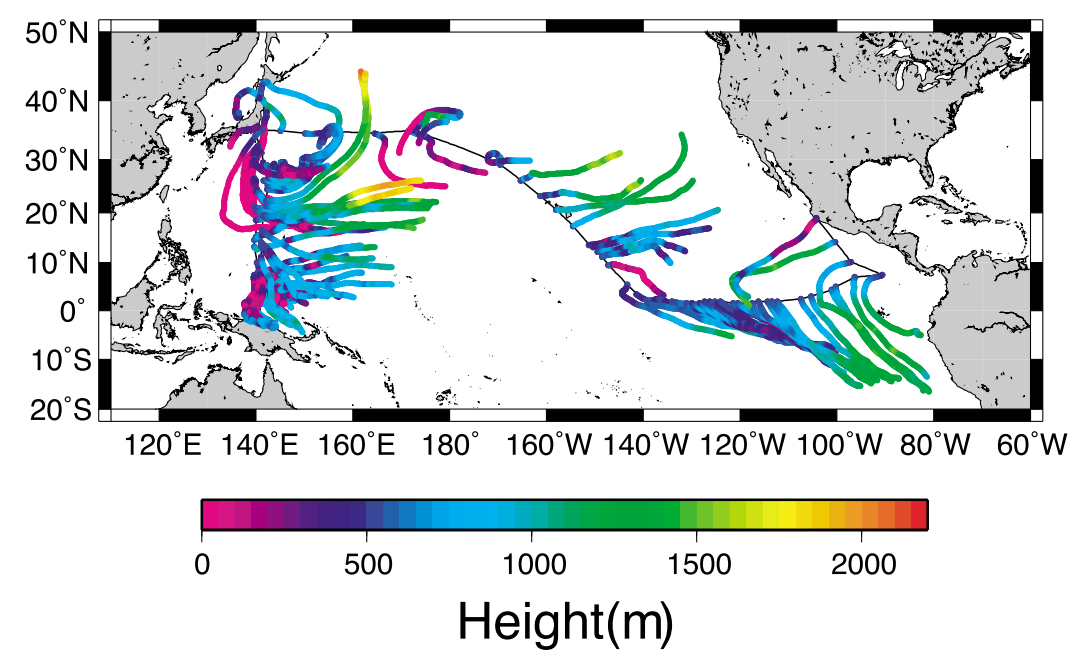

Figure 2. Five-day back trajectories for air masses arriving at $500 \mathrm{~m}$ altitude over the sampling locations. Trajectories were calculated with Meteorological Data Explorer (METEX) (http://db.cger.nies.go.jp/metex/ index.html, Center for Global Environmental Research, National Institute for Environmental Studies, Japan). Black lines show the cruise tracks.

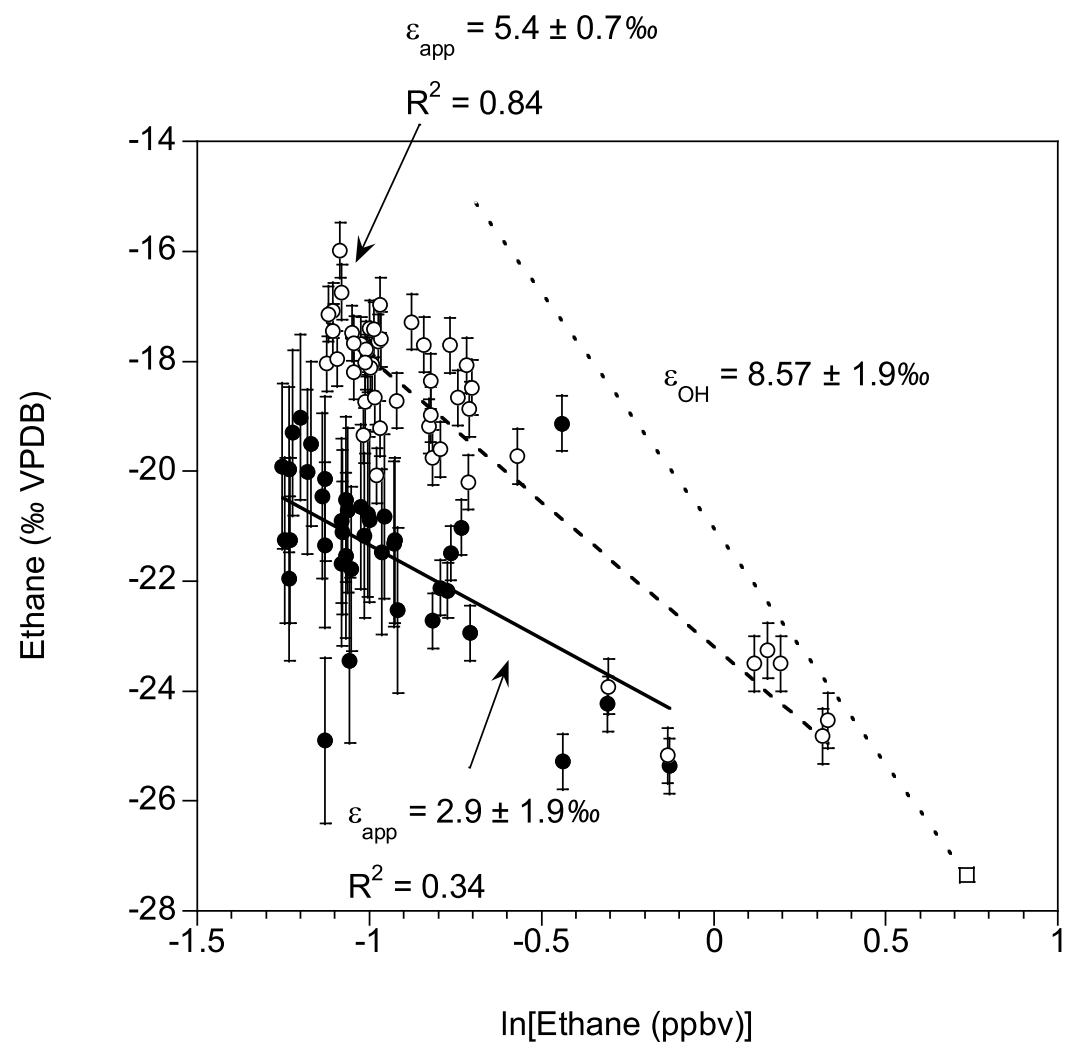

Figure 3. Mixing ratios versus stable carbon isotope ratios of ethane for the trans-Pacific cruise (solid circles) and the western North Pacific cruise (open circles). Error bars indicate $1 \sigma$ uncertainty of the isotopic measurements. The open square indicates the mean mixing ratio and isotopic ratio in an urban atmosphere, as reported by Tsunogai et al. [1999]. The solid and dashed lines show the linear least squares fits to the trans-Pacific cruise and the western North Pacific cruise, respectively. The dotted line indicates the Rayleigh dependence for reaction of ethane with $\mathrm{OH}$ radicals $\left(\mathrm{KIE}_{\mathrm{OH}}=8.57 \%\right)$, based on average urban values. 
Table 1. Annual Global Emission Strengths of Ethane and Their Relevant $\delta^{13} \mathrm{C}$ Values Used for the Global Chemical Transport Modeling

\begin{tabular}{lcc}
\hline \multicolumn{1}{c}{ Source } & $\begin{array}{c}\text { Emission Strength } \\
\left(\mathrm{Tg} \mathrm{yr}^{-1}\right)\end{array}$ & $\begin{array}{c}\delta^{13} \mathrm{C} \\
(\%)\end{array}$ \\
\hline Gas production and transmission & 1.83 & -32 \\
Oil production and transmission & 1.36 & -26 \\
Other fossil fuel and industrial fuel & 1.46 & -26 \\
$\quad$ combustion & & \\
Biomass burning from C3 plants & $2.0,{ }^{\mathrm{a}} 1.6^{\mathrm{b}}$ & -27 \\
Biomass burning from C4 plants & $0.9,{ }^{\mathrm{a}} 0.7^{\mathrm{b}}$ & -13 \\
Biogenic/vegetation & 0.8 & -27 \\
Ocean & 0.1 & -40 \\
Total & $8.45,{ }^{\mathrm{a}} 7.85^{\mathrm{b}}$ & \\
\hline
\end{tabular}

${ }^{\mathrm{a}}$ For 1999

${ }^{\mathrm{b}}$ For 2000.

\subsection{Comparison of the Observations With Model Calculations}

[13] The observed variabilities of atmospheric ethane and its $\delta^{13} \mathrm{C}$ were compared with the results of a global threedimensional chemical transport model, MOZART-3 (Model for Ozone and Related Tracers, version 3). Technical details of the model have been reported by Kinnison et al. [2007], and details of its application to stable carbon isotope ratios of ethane have been reported by Stein and Rudolph [2007]. Briefly, the model included chemistry and transport as well as sources and sinks for 115 chemical tracers involved in 315 chemical reactions. It was driven by meteorological fields from the European Centre for Medium-Range Weather Forecasts for 1999 and 2000 . Model resolution was $1.875^{\circ} \times$ $1.875^{\circ}$ with 60 vertical levels from the surface to $0.1 \mathrm{hPa}$; ethane fields were output every three simulation hours. The ethane emission data, except those from biomass burning, were from the work of Stein and Rudolph [2007], which in turn used emission inventory data based on the Emission Database for Global Atmospheric Research, version 2.0 (EDGAR) [Olivier et al., 1996]. Emissions of ethane from biomass burning were based on the Global Fire Emissions Database, version 2 (GFEDv2) [van der Werf et al., 2006]. Most of the source-specific isotope ratios of ethane used here were identical to those in the work of Stein and Rudolph [2007], whereas the isotopic signature of ethane emitted from the ocean was changed from $-22 \%$ to $-40 \%$ in accordance with recent observations in the western North Pacific [Kameyama et al., 2009]. Table 1 summarizes the emission strengths and source-specific stable carbon isotope ratios that we used. Simulations of ethane were performed separately for two isotopologues, ${ }^{12} \mathrm{C}_{2} \mathrm{H}_{6}$ and ${ }^{13} \mathrm{C}_{2} \mathrm{H}_{6}$. These isotopologues behave identically to each other, except for a slight difference in the rate constant of the reaction with $\mathrm{OH}$ radicals due to the $\mathrm{KIE}_{\mathrm{OH}}\left(\varepsilon_{\mathrm{OH}}=8.57 \%\right.$ o $\pm 1.95 \%$ [Anderson et al., 2004]).

[14] We calculated the mixing ratios of ethane and its $\delta^{13} \mathrm{C}$ values in the global atmosphere, and present their spatial and temporal distributions near the surface over the North Pacific in Figure 4. The model calculations describe reasonably well the main features of the spatial variability of ethane; e.g., the calculated mixing ratios and $\delta^{13} \mathrm{C}$ values were high and low, respectively, over urban regions in the mid latitudes, while low and high over the remote North Pacific. The modeled mixing ratios with locations and times corresponding to the shipboard samples were extracted from the model output fields and compared with the observations (Figure 5a). The model reproduced the spatial distribution patterns of ethane reasonably $\left(R^{2}=0.46\right)$, but the observed values of the mixing ratios were approximately 1.8 times larger than the absolute values in the model. This discrepancy was likely due to the underestimation of emission strengths in the model, because the total emission strength $\left(8.45 \mathrm{Tg} \mathrm{yr}^{-1}\right.$ in 1999 and $7.85 \mathrm{Tg} \mathrm{yr}^{-1}$ in 2000) used in our study was substantially lower than top-down estimates of global ethane sources (15.5 $\mathrm{Tg} \mathrm{yr}^{-1}$ [Rudolph, 1995]; $13.0 \mathrm{Tg} \mathrm{yr}^{-1}$ [Xiao et al., 2008]). Underestimation by the models based on EDGAR V2.0 is consistent with the results of previous studies [e.g., Stein and Rudolph, 2007; Thompson et al., 2003].

[15] In contrast to the underestimation of mixing ratios, MOZART-3 predicted higher $\delta^{13} \mathrm{C}$ than the observations: the calculated values were mostly above $-17 \%$ over the lowlatitudinal $\left(0^{\circ} \mathrm{N}\right.$ to $\left.30^{\circ} \mathrm{N}\right)$ North Pacific (Figures $4 \mathrm{c}$ and $\left.4 \mathrm{~d}\right)$, whereas the observations ranged from $-16 \%$ to $-21 \%$ (Figure 1 and Figure 5b). To interpret this difference, it should be noted that the calculated $\delta^{13} \mathrm{C}$ values were associated with uncertainties arising from (1) the model chemistry (removal of ethane by $\mathrm{OH}$ radicals), (2) transport, (3) the distribution of emission sources, (4) the source-specific isotope ratios, and (5) the $\mathrm{KIE}_{\mathrm{OH}}$. Among these, the first three uncertainties would affect both mixing ratio and $\delta^{13} \mathrm{C}$, whereas the last two uncertainties affect only $\delta^{13} \mathrm{C}$ [Thompson et al., 2003]. Although the model did not reproduce the absolute values of the observed mixing ratios as discussed above, it did reproduce the distribution patterns. The uncertainties in the chemistry, transport, and distribution of emission sources are therefore likely to be reasonably small. Although the total emission strength was too low, its uncertainties would not have affected the calculated $\delta^{13} \mathrm{C}$ [Thompson et al., 2003].

[16] The uncertainties associated with the source-specific isotope ratios are difficult to quantify because of the limited number of relevant studies. The most important sources, such as leakage of natural gas or biomass burning of $\mathrm{C} 3$ plants, have $\delta^{13} \mathrm{C}$ values of ethane of around $-27 \%$ (Table 1$)$. The model predicted similar values over the source regions (e.g., urban areas in East Asia), being consistent with ambient $\delta^{13} \mathrm{C}$ measurements made near the regions [Saito et al., 2009; Tsunogai et al., 1999]. Sources that have quite different $\delta^{13} \mathrm{C}$ signatures are biomass burning of $\mathrm{C} 4$ plants $(-13 \%)$ and oceanic emissions ( $-40 \%$ ) (Table 1$)$. C4 plant burning yields relatively small emissions on a global scale, and its major source regions (e.g., tropical Africa; see Stein and Rudolph [2007], Figure 1) are far from the studied regions, so the impact of the uncertainty of this factor on the calculated $\delta^{13} \mathrm{C}$ would have been relatively small. The emission strength of the oceanic source is negligibly small on a global scale ( $\sim 1 \%$ of the total; see Table 1$)$. However, this source may be important in the remote marine atmosphere, which we studied here. To assess this possibility, we estimated the contribution of oceanic emissions by using a simple model with reported values for sea-to-air flux $\left(0.15 \pm 0.12 \times 10^{8}\right.$ molecules $\mathrm{cm}^{-2} \mathrm{~s}^{-1}$ [Plass-Dülmer et al., 1995]) of ethane into a boundary layer (height of $1 \mathrm{~km}$ ) and for removal by $\mathrm{OH}$ radicals $\left(\mathrm{k}_{\mathrm{OH}}=1.3 \times 10^{7} \mathrm{~cm}^{-3}\right.$ [Atkinson, 1997]). The mixing ratio of ethane emitted from oceanic sources was thus estimated to be $0.018 \pm 0.015 \mathrm{ppbv}$, accounting for only $4 \pm 3 \%$ 
a)

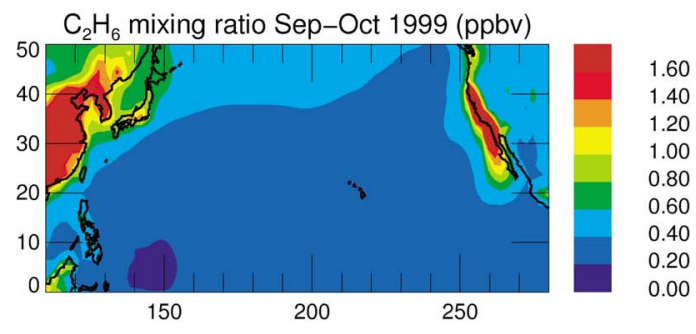

c)

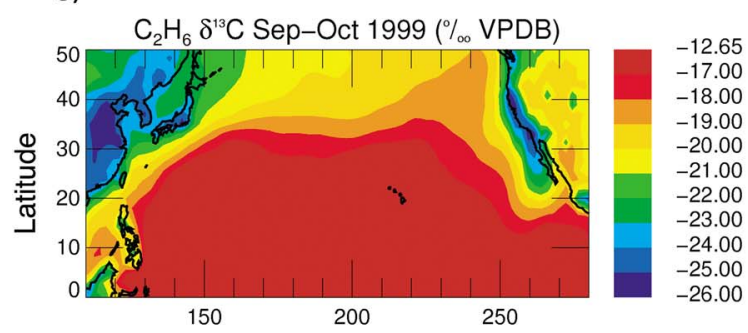

e)

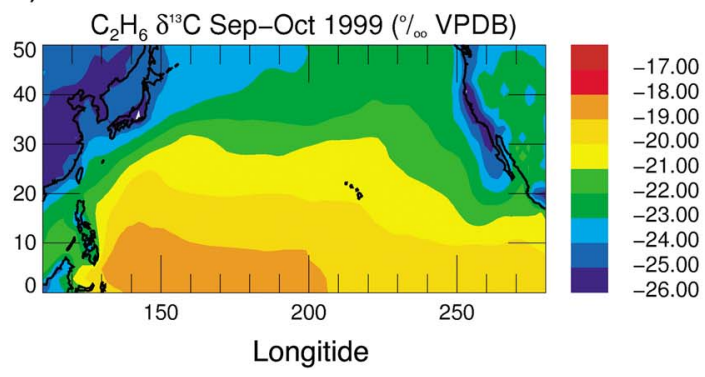

b)

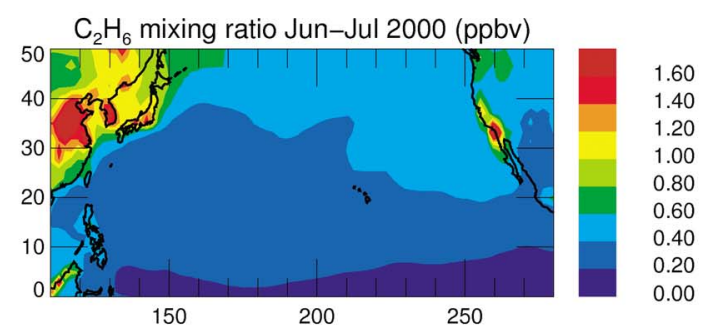

d)

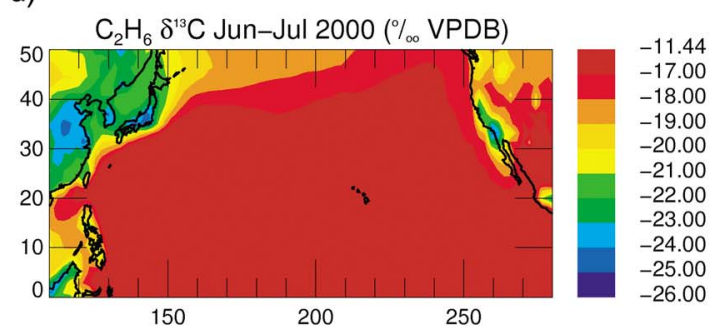

f)

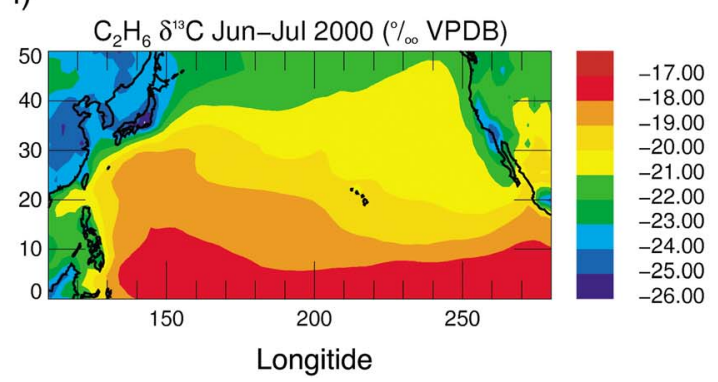

Figure 4. Modeled (a, b) mean mixing ratios and (c-f) mean stable carbon isotope ratios of ethane over the North Pacific (approximately lowest $40 \mathrm{~m}$ ) for (left) autumn 1999 and (right) summer 2000. The stable carbon isotope ratios were calculated with a $\mathrm{KIE}_{\mathrm{OH}}$ of $8.57 \%$ (Figures $4 \mathrm{c}$ and $4 \mathrm{~d}$ ) and 5.26\% (Figures 4e and 4f).

of the observed mean mixing ratios. Assuming the uncertainty range of $\delta^{13} \mathrm{C}$ in the oceanic source to be $\sim 10 \%$ [Kameyama et al., 2009], the resulting change in the atmospheric $\delta^{13} \mathrm{C}$ of ethane would be $\sim 0.5 \%$, which is comparable to the measurement uncertainty. Therefore, it is unlikely that the uncertainty of this source has a major impact on the atmospheric $\delta^{13} \mathrm{C}$ of ethane.

[17] The uncertainty in $\mathrm{KIE}_{\mathrm{OH}}$ for ethane has been reported to be larger than those for the other alkanes [Anderson et al., 2004]. If we were to use the lowest value (5.26\%) of the reported $\mathrm{KIE}_{\mathrm{OH}}$ within the $95 \%$ confidence interval, instead of the mean value $\left(8.57 \%\right.$ ), the calculated $\delta^{13} \mathrm{C}$ values of ethane would decrease down to $-16 \%$ to $-21 \%$ over the low latitudes $\left(0^{\circ} \mathrm{N}\right.$ to $\left.30^{\circ} \mathrm{N}\right)$ in the North Pacific with a gradual increase from the north to south (Figures $4 \mathrm{e}$ and $4 \mathrm{f}$ ). The recalculated $\delta^{13} \mathrm{C}$ values were much closer to the observations (Figure 5c). The strong impact of the change in $\mathrm{KIE}_{\mathrm{OH}}$ could be attributed to the fact that chemical removal of ethane is the most important factor governing the observed $\delta^{13} \mathrm{C}$ variability over the remote areas in summer-autumn, which is characterized by high $\mathrm{OH}$ radical concentrations. Although $\mathrm{OH}$ oxidation is generally thought to dominate the atmospheric removal of ethane, some papers have presented a significant role for chlorine atoms in the marine boundary layer [e.g., Pszenny et al., 2007]; this role was not taken into account in our model. However, KIE in the reaction with $\mathrm{Cl}$ atoms [Anderson et al., 2007] is larger than $\mathrm{KIE}_{\mathrm{OH}}$ (i.e., leading to a higher ambient $\delta^{13} \mathrm{C}$ than does $\mathrm{OH}$ oxidation alone), and thus this loss would not explain the model overestimation of $\delta^{13} \mathrm{C}$. Further, it should be noted that the model shows much higher values for low isotope ratio data (Figure 5c), indicating the uncertainty in $\mathrm{KIE}_{\mathrm{OH}}$ is not the only source of the discrepancy.

\section{Conclusions}

[18] The successful modeling with low $\mathrm{KIE}_{\mathrm{OH}}$ suggested that the laboratory experiment overestimated $\mathrm{KIE}_{\mathrm{OH}}$ by about $3 \%$, accounting for approximately $40 \%$ of the mean $\mathrm{KIE}_{\mathrm{OH}}$, although the value was still within the uncertainty. This might support our previous finding [Saito et al., 2009] of similar photochemical ages of ethane and acetylene over east Asia, despite the fact that the atmospheric lifetime of ethane is three times that of acetylene; overestimation of the reported $\mathrm{KIE}_{\mathrm{OH}}$ might have caused the similarities in age. However, we emphasize that the above implication is associated with 
a)

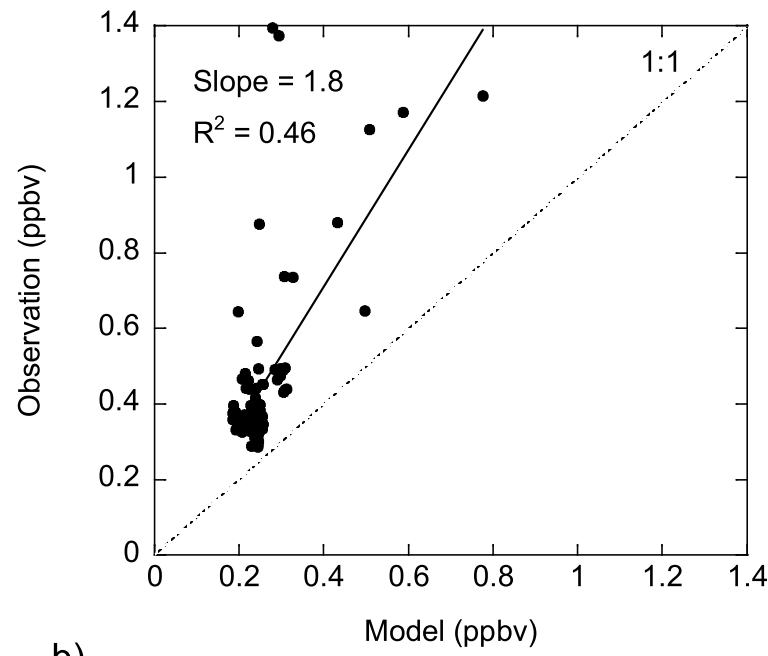

b)

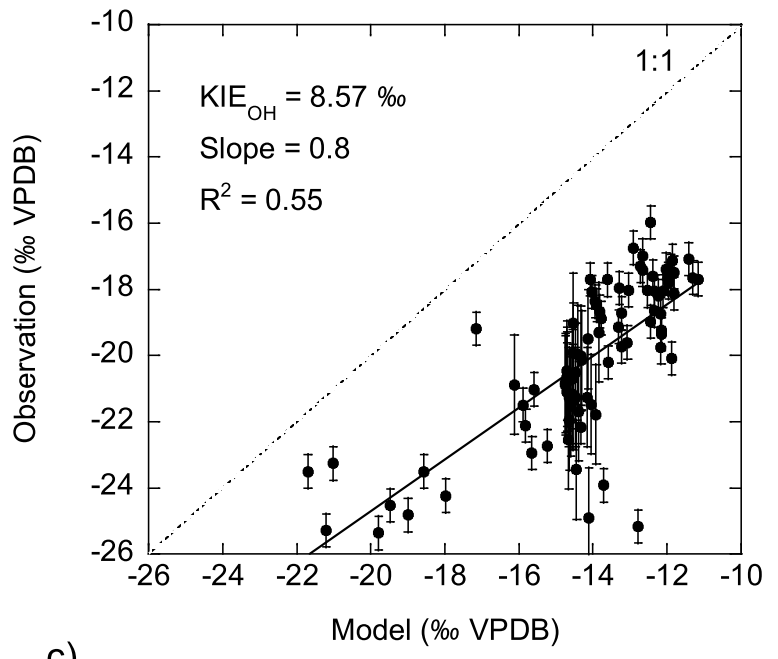

c)

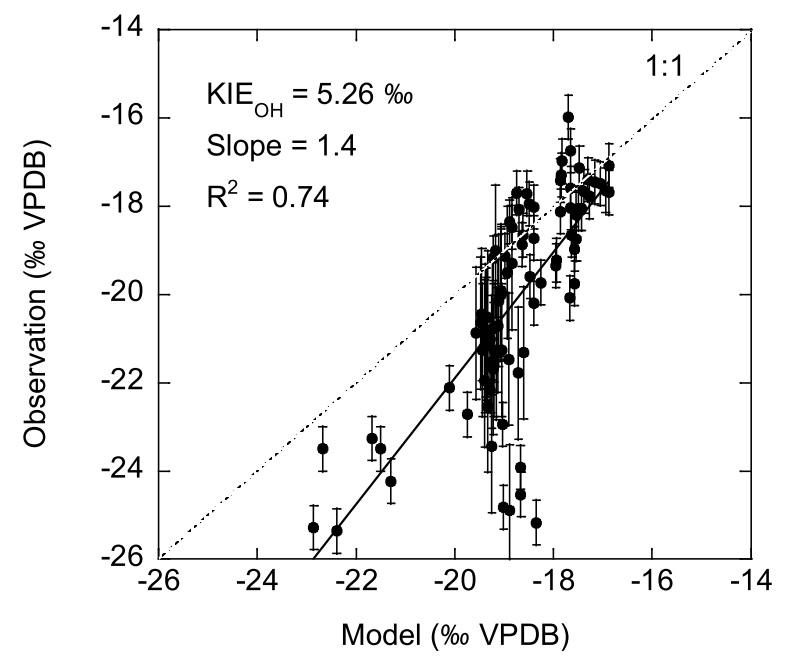

Figure 5. Correlations between model results and observations of ethane for (a) mixing ratios and (b, c) stable carbon isotope ratios. The calculations were made with a KIE of 8.57\% (Figure 5b) and 5.26\% (Figure 5c). considerable potential uncertainty because (1) it is based on a comparison between limited numbers of atmospheric measurements and the modeling and (2) an unidentified substantial source of ethane might have an impact on the atmospheric $\delta^{13} \mathrm{C}$ of ethane. For a more accurate estimate of $\mathrm{KIE}_{\mathrm{OH}}$, more reliable laboratory experiments on the reaction of ethane with $\mathrm{OH}$ radicals are essential.

[19] Acknowledgments. We thank Masahiro Narukawa and the crews of R/V Shoyo-maru and R/V Mirai for their help in collecting air samples. This study was supported partly by Research Fellowships of the Japan Society for the Promotion of Science for Young Scientists to T.S. and by Core Research for Evolutional Science and Technology (CREST), Japan Science and Technology Corporation, to the Tokyo Institute of Technology.

\section{References}

Anderson, R. S., L. Huang, R. Iannone, A. E. Thompson, and J. Rudolph (2004), Carbon kinetic isotope effects in the gas phase reactions of light alkanes and ethene with the $\mathrm{OH}$ radical at $296 \pm 4 \mathrm{~K}, J$. Phys. Chem. A, 108(52), 11,537-11,544, doi:10.1021/jp0472008.

Anderson, R. S., L. Huang, R. Iannone, and J. Rudolph (2007), Measurements of the ${ }^{12} \mathrm{C} /{ }^{13} \mathrm{C}$ kinetic isotope effects in the gas-phase reactions of light alkanes with chlorine atoms, J. Phys. Chem. A, 111(3), 495-504, doi:10.1021/jp064634p.

Atkinson, R. (1997), Gas-phase tropospheric chemistry of volatile organic compounds: 1. Alkanes and alkenes, J. Phys. Chem. Ref. Data, 26(2), 215-290, doi:10.1063/1.556012.

Bill, M., M. E. Conrad, and A. H. Goldstein (2004), Stable carbon isotope composition of atmospheric methyl bromide, Geophys. Res. Lett., 31(4), L04109, doi:10.1029/2003GL018639.

Blake, D. (2005), Methane, nonmethane hydrocarbons, alkyl nitrates, and chlorinated carbon compounds including 3 chlorofluorocarbons (CFC-11, CFC-12, and CFC-113) in whole-air samples, in Trends: A Compendium of Data on Global Change, edited by T. A. Boden et al., Carbon Dioxide Inf. Anal. Cent., Oak Ridge Natl. Lab., U.S. Dep. of Energy, Oak Ridge, Tenn. (Available at http://cdiac.ornl.gov/trends/ otheratg/blake/blake.html.)

Blake, D. R., N. J. Blake, T. W. Smith, O. W. Wingenter, and F. S Rowland (1996a), Nonmethane hydrocarbon and halocarbon distributions during Atlantic Stratocumulus Transition Experiment/Marine Aerosol and Gas Exchange, June 1992, J. Geophys. Res., 101(D2), 4501-4514, doi:10.1029/95JD01370.

Blake, D. R., T. Y. Chen, T. Y. Smith, C. J. L. Wang, O. W. Wingenter, N. J. Blake, F. S. Rowland, and E. W. Mayer (1996b), Threedimensional distribution of nonmenthane hydrocarbons and halocarbons over the northwestern Pacific during the 1991 Pacific Exploratory Mission (PEM-West A), J. Geophys. Res., 101(D1), 1763-1778, doi:10.1029/95JD02707.

Blake, N. J., D. R. Blake, T. Y. Chen, J. E. Collins, G. W. Sachse, B. E. Anderson, and F. S. Rowland (1997), Distribution and seasonality of selected hydrocarbons and halocarbons over the western Pacific basin during PEM-West A and PEM-West B, J. Geophys. Res., 102(D23), 28,315-28,331, doi:10.1029/97JD02538.

Goldstein, A. H., S. C. Wofsy, and C. M. Spivakovsky (1995), Seasonal variations of nonmethane hydrocarbons in rural New England: Constraints on $\mathrm{OH}$ concentrations in northern midlatitudes, J. Geophys. Res., 100(D10), 21,023-21,033, doi:10.1029/95JD02034.

Helmig, D., D. M. Tanner, R. E. Honrath, R. C. Owen, and D. D. Parrish (2008), Nonmethane hydrocarbons at Pico Mountain, Azores: 1. Oxidation chemistry in the North Atlantic region, J. Geophys. Res., 113, D20S91, doi:10.1029/2007JD008930.

Kameyama, S., et al. (2009), Enrichment of alkanes within a phytoplankton bloom during an in situ iron enrichment experiment in the western subarctic Pacific, Mar. Chem., 115(1-2), 92-101, doi:10.1016/j.marchem. 2009.06.009.

Keppler, F., D. B. Harper, T. Rockmann, R. M. Moore, and J. T. G. Hamilton (2005), New insight into the atmospheric chloromethane budget gained using stable carbon isotope ratios, Atmos. Chem. Phys., 5, 2403-2411, doi:10.5194/acp-5-2403-2005.

Kinnison, D. E., et al. (2007), Sensitivity of chemical tracers to meteorological parameters in the MOZART-3 chemical transport model, J. Geophys. Res., 112, D20302, doi:10.1029/2006JD007879.

Nara, H., S. Toyoda, and N. Yoshida (2007), Measurements of stable carbon isotopic composition of ethane and propane over the western North Pacific and eastern Indian Ocean: A useful indicator of atmospheric 
transport process, J. Atmos. Chem., 56(3), 293-314, doi:10.1007/s10874006-9057-3.

Olivier, J. G. J., A. F. Bouwman, C. W. M. Van der Maas, J. J. M Berdowski, C. Veldt, J. P. J. Bloos, A. J. H. Visschedijk, P. Y. J. Zandveld, and J. L. Haverlag (1996), Description of EDGAR Version 2.0: A Set of Global Emission Inventories of Greenhouse Gases and OzoneDepleting Substances for All Anthropogenic and Most Natural Sources on a per Country Basis and on $1^{\circ} \times 1^{\circ}$ Grid, RIVM Rep. 771060002, xxix +141 pp., Natl. Inst. for Public Health and the Environ., Bilthoven, Netherlands.

Parrish, D. D., C. J. Hahn, E. J. Williams, R. B. Norton, F. C. Fehsenfeld, H. B. Singh, J. D. Shetter, B. W. Gandrud, and B. A. Ridley (1992), Indications of photochemical histories of Pacific air masses from measurements of atmospheric trace species at Point Arena, California, J. Geophys. Res., 97(D14), 15,883-15,901.

Plass-Dülmer, C., R. Koppmann, M. Ratte, and J. Rudolph (1995), Light nonmethane hydrocarbons in seawater, Global Biogeochem. Cycles, 9(1), 79-100, doi:10.1029/94GB02416.

Pszenny, A. A. P., E. V. Fischer, R. S. Russo, B. C. Sive, and R. K. Varner (2007), Estimates of $\mathrm{Cl}$ atom concentrations and hydrocarbon kinetic reactivity in surface air at Appledore Island, Maine (USA), during International Consortium for Atmospheric Research on Transport and Transformation/Chemistry of Halogens at the Isles of Shoals, J. Geophys. Res., 112, D10S13, doi:10.1029/2006JD007725.

Rudolph, J. (1995), The tropospheric distribution and budget of ethane, J. Geophys. Res., 100(D6), 11,369-11,381, doi:10.1029/95JD00693.

Rudolph, J., and E. Czuba (2000), On the use of isotopic composition measurements of volatile organic compounds to determine the "photochemical age" of an air mass, Geophys. Res. Lett., 27(23), 3865-3868, doi:10.1029/2000GL011385.

Rudolph, J., D. C. Lowe, R. J. Martin, and T. S. Clarkson (1997), A novel method for compound specific determination of $\delta^{13} \mathrm{C}$ in volatile organic compounds at ppt levels in ambient air, Geophys. Res. Lett., 24(6), 659662, doi:10.1029/97GL00537.

Saito, T., and Y. Yokouchi (2008), Stable carbon isotope ratio of methyl chloride emitted from glasshouse-grown tropical plants and its implication for the global methyl chloride budget, Geophys. Res. Lett., 35 , L08807, doi:10.1029/2007GL032736.

Saito, T., Y. Yokouchi, and K. Kawamura (2000), Distributions of $\mathrm{C}_{2}-\mathrm{C}_{6}$ hydrocarbons over the western North Pacific and eastern Indian Ocean Atmos. Environ., 34(25), 4373-4381, doi:10.1016/S1352-2310(00) 00249-1.

Saito, T., U. Tsunogai, K. Kawamura, T. Nakatsuka, and N. Yoshida (2002), Stable carbon isotopic compositions of light hydrocarbons over the western North Pacific and implication for their photochemical ages, J. Geophys. Res., 107(D4), 4040, doi:10.1029/2000JD000127.

Saito, T., K. Kawamura, T. Nakatsuka, and B. J. Huebert (2004), In situ measurements of butane and pentane isomers over the subtropical North Pacific, Geochem. J., 38(5), 397-404.
Saito, T., K. Kawamura, U. Tsunogai, T.-Y. Chen, H. Matsueda, T. Nakatsuka, T. Gamo, M. Uematsu, and B. J. Huebert (2009), Photochemical histories of nonmethane hydrocarbons inferred from their stable carbon isotope ratio measurements over east Asia, J. Geophys. Res., 114, D11303, doi:10.1029/2008JD011388.

Spivakovsky, C. M., et al. (2000), Three-dimensional climatological distribution of tropospheric OH: Update and evaluation, J. Geophys. Res. 105(D7), 8931-8980, doi:10.1029/1999JD901006.

Stein, O., and J. Rudolph (2007), Modeling and interpretation of stable carbon isotope ratios of ethane in global chemical transport models, J. Geophys. Res., 112, D14308, doi:10.1029/2006JD008062.

Thompson, A. E., R. S. Anderson, J. Rudolph, and L. Huang (2002), Stable carbon isotope signatures of background tropospheric chloromethane and CFC113, Biogeochemistry, 60(2), 191-211, doi:10.1023/ A: 1019820208377

Thompson, A., J. Rudolph, F. Rohrer, and O. Stein (2003), Concentration and stable carbon isotopic composition of ethane and benzene using a global three-dimensional isotope inclusive chemical tracer model, J. Geophys. Res., 108(D13), 4373, doi:10.1029/2002JD002883.

Tsunogai, U., N. Yoshida, and T. Gamo (1999), Carbon isotopic compositions of $\mathrm{C}_{2}-\mathrm{C}_{5}$ hydrocarbons and methyl chloride in urban, coastal, and maritime atmospheres over the western North Pacific, J. Geophys. Res., 104(D13), 16,033-16,039, doi:10.1029/1999JD900217.

van der Werf, G. R., J. T. Randerson, L. Giglio, G. J. Collatz, P. S. Kasibhatla, and A. F. Arellano Jr. (2006), Interannual variability in global biomass burning emissions from 1997 to 2004, Atmos. Chem Phys., 6(11), 3423-3441, doi:10.5194/acp-6-3423-2006.

Xiao, Y., J. A. Logan, D. J. Jacob, R. C. Hudman, R. Yantosca, and D. R. Blake (2008), Global budget of ethane and regional constraints on U.S. sources, J. Geophys. Res., 113, D21306, doi:10.1029/2007JD009415.

T. Gamo, Ocean Research Institute, University of Tokyo, 1-15-1 Minamidai, Nakano-ku, Tokyo 164-8639, Japan.

K. Kawamura, Institute of Low Temperature Science, Hokkaido University, N19 W8, Kita-ku, Sapporo 060-0819, Japan.

T. Nakatsuka, Graduate School of Environmental Studies, Nagoya University, Furo-cho, Chikusa-ku, Nagoya 464-8601, Japan.

T. Saito, Environmental Chemistry Division, National Institute for Environmental Studies, 16-2 Onogawa, Tsukuba, Ibaraki 3058506, Japan. (saito.takuya@nies.go.jp)

O. Stein, Institut für Energie- und Klimaforschung - Troposphäre (IEK-8), Forschungszentrum Jülich, D-52425 Jülich, Germany.

U. Tsunogai, Graduate School of Science, Hokkaido University, N10 W8, Kita-ku, Sapporo 060-0810, Japan.

N. Yoshida, Department of Environmental Science and Technology, Interdisciplinary Graduate School of Science and Engineering, Tokyo Institute of Technology, G1-25, 4259 Nagatsuta, Midori-ku, Yokohama 226-8502, Japan. 